\title{
Will Self-Monitoring Enhance the Relational Dimension of Workplace Spirituality?
}

Rohini S. Nair ${ }^{1 *}$, Dr. V. Sivakumar ${ }^{2}$

${ }^{1}$ Research Scholar, ${ }^{2}$ Associate Professor, Alagappa University, Karaikudi, Tamil Nadu, India

Workplace Spirituality is a concept that has gained traction in the recent years. It has been proved to be a very beneficial construct for individuals and organizations. Out of the dimensions of workplace spirituality, relational dimension (connection) is considered by many researchers to be the most vital. This dimension is about building and maintaining relationship with co-workers and community. But, this depends on the personality of an individual. Some are able to make relationships much faster than others as they have the ability to understand others' emotions and modify their behaviour accordingly to suit the setting. Such people are called high self-monitors. Low self-monitors, on the other hand, always try to portray their true inner self. The relational dimension of workplace spirituality is about creating genuine relationships with the co-workers. In such a context, the question that rises is whether high selfmonitors or low self-monitors are the best suited.

Keywords: High Self-Monitors, Low Self-monitors, Relational Dimension, Self-monitoring, Workplace Spirituality. Copyright @ 2020: This is an open-access article distributed under the terms of the Creative Commons Attribution license which permits unrestricted use, distribution, and reproduction in any medium for non-commercial use (NonCommercial, or CC-BY-NC) provided the original author and source are credited.

\section{INTRODUCTION}

With changes in the outlook of individuals towards work and workplace, emphasis is also on building good relationship with co-workers. People spend majority of their time in their work setting rather than with their family and social circle. Creating better relationships at work creates a positive and productive environment. These relationships can have a positive or a negative impact on the job satisfaction of employees. Good relationships in the workplace increases employee morale and create a positive workplace. With better relationships, people tend to work well together. This will also promote an environment of trust and respect for each other. It will also result in people feeling more connected to their workplace and will tend to remain with the organization, thereby, reducing the rate of attrition. All these elements added together will provide numerous benefits to the organization as a whole. "Establishing and maintaining effective work relationships allow for task coordination, information flow, and other work processes that are necessary for accomplishing the goals and objectives of an organization [1]". Creating and maintaining a contented and well-adjusted workforce is the key to success for any organization.
Personality is the most important factor in determining the quality and quantity of an individual's relationship. A person who is capable of regulating and controlling behaviour to suit the situations (selfmonitoring) are found to be better in building The socio-analytic theory (the theory behind the concept of self-monitoring) is about getting along, getting ahead, and making sense. Existing good relationships in the workplace setting. "Research indicates that high selfmonitors are particularly good at getting along (e.g., meeting others' social expectations) and getting ahead (e.g., job performance and leadership emergence) [1] ". High self-monitors are found to get along well with others. Their personalities seem to be outgoing and engaging. "High self-monitors focus on emotional and behavioural cues displayed by others in social situations. High self-monitors read nuances of behaviour in others so that they can alter their own behaviour and act appropriately in social situations" [2]. This quality will help individuals to build good relationship with co-workers and to remain connected to their workplace.

\section{THEORETICAL BACKGROUND Workplace Spirituality \\ Workplace Spirituality has emerged as a significant concept for organizations due to the change}


in people's mind set and increasing competition faced by the organizations. Satisfying stakeholders is the most important challenge faced by modern organizations and this result in employees working under very stressful situations to meet this objective. "If the workplace is enjoyable, the productivity of organization increases manifolds, because when employees are happy and enjoying the work they can work even harder [3]". With work taking over majority of people's time, work and workplace have taken prominent positions in their lives. “As a result, workers' need for connectedness, meaning, purpose, altruism, virtue, nurturance, and hope in one's work and at one's workplace likely is also at an all-time high" [4]. Workplace spirituality was described by Krishnan, V.R. [5] as "oneness with all other beings". In his opinion, "spirituality is the integration of three dimensions- first is the knowledge base and belief systems of an individual, second is one's interior life and inner self and the third dimension is exterior life and institutional activity".

Workplace spirituality is described by Kinjerski and Skrypnek [7] as, "the experience of employees who are passionate about and energized by their own work, find meaning and purpose in their work, feel they can express their complete selves at work, and feel connected to those with whom they work". A much deeper definition of workplace spirituality was given by Giacalone and Jurkiewicz [8]. They defines it as, "a framework of organizational values evidence in the culture that promotes employees' experience of transcendence through the work process, facilitating their sense of being connected to others in a way that provides feelings of completeness and joy". Pfeffer [10] identified that workplace spirituality, "allowed the employees to learn and develop interesting works, provided meaningful works, constructed significant social relationships among co- workers and trained employees to face different lives". According to Mahoney and Graci [11], "spirituality involves a sense of giving and service, a sense of connection (community), compassion and forgiveness, meaning, and morality".

According to Krishnakumar and Neck [12], the concept of workplace spirituality includes "notions of inner consciousness, and a search for meaning". Guillory [13] argued that "spirituality is the domain of inner consciousness that expresses itself as a sense of "harmony, interconnectedness, and oneness". Jurkiewicz and Giacalone [14] has pointed out the positive impacts of workplace spirituality on employees which includes, "creativity, honesty, trust, selfrealization, commitment, and improved adaptability". Workplace spirituality is also found to increase employees' involvement level. It is also found to improve "self-image and the extent to which the individual identifies psychologically with his or her job [15]. In the words of Bandsuch and Cavanagh [16], "workplace spirituality also provides productive values in terms of greater retention and loyalty, rectifies social alienation and realizes the power of individual productivity and creativity".

Workplace spirituality has been described by several researchers at the individual level, group level and organizational level. Several dimensions of workplace spirituality have been discovered by researchers. Wong [17] have developed a seven dimension scale of workplace spirituality. These dimensions include creativity, communication, vision, partnership, positive energy, flexibility and respect towards one another. The most common and widely used scale dimensions of workplace spirituality were developed by Milliman et al. [18]. The dimensions put forward by them at the different levels are, "meaningful work (individual phase), sense of community/relational (group phase) and coherent with organizational values (organizational phase)". The first dimension, meaningful work, describes "the individuals' in-depth feelings toward work meaning and purpose and connection between work and the meaning of life [19]". The second dimension, sense of community is "considered as the most critical dimension as it involves relationship with others that cultivates the communal sense $[20,21]$. The third dimension, alignment with organizational values refers to "the interaction between organizational values and the employees [22].

\section{Relational Dimension of Workplace Spirituality}

Workplace spirituality, according to Kinjerski and Skrypnek [6], "arises primarily from interactions among personality traits, personal actions and organizational features, focusing attention on organizational contexts and cultures that act as spirituality-friendly and fostering environments and is also said to influence the extent to which an organization enables employees to integrate their whole selves and values into everyday work". Relational dimension (sense of community) is described by Ashmos and Duchon [20] and Milliman et al. [21] as, "how people see themselves and connect with each other, including support, freedom of expression and genuine caring". This dimension is considered to be the most important as this creates a strong perception of being connected with their co-workers and this will result in a positive work environment and will also impact their performance and commitment towards their work and organization.

The interaction between the employees will also play a key role in enhancing the sharing of knowledge between them. This involves "better social interactions and transformation" among people [23]. It also results in "a deep sense of connectedness and greater mutual understanding [24]". According to Nonaka et al., [23], "people see themselves as related to others in terms of values, perceptions and synthesis of subjective viewpoints". Rego et al. [25] and Pawar, S. [26] consider workplace spirituality necessary "as it 
creates a strong sense of community among employees and this connection will improve their psychological well-being". Krishnakumar and Neck [12] have said that the relational dimension will "enhance the employees' family life, including recreation and social activities".

According to Duchon and Plowman [27], "connection is defined as one's experience of a deep sense of connection with other people and other people's work and feels part of the community and can identify him/herself with the group's common purpose". Wong, et al. [28] explains that "employees who are strongly committed and share a strong relationship with their organization and co-workers are more concerned about their and organization's performance". Sheng, Chieh-Wen and Chen, Ming-Chia [29] referred to the relational dimension as "the interpersonal and profound connections and relationships". They also described that "the employees who had in-depth interactions with others had enhanced mutual inner feelings and even sympathy with others' inner selves". According to Brown [19], "this community relationship improves trust, support, communication, and sincere care. Thus, the employees in the organization would care for and support each other resulting in a positive work environment".

The dimension of sense of community creates "an attitude of sharing and a sense of togetherness with each other both within one's department as well as in the organization" [30]. Ashmos and Duchon [20] has further described that "the condition for the community includes the notion of sharing, mutual obligations, and commitments that connect one individual to another". "This is a very critical dimension that will help employees feel themselves part of a larger community that can be interconnected, and can build soul and spirit [9]. This dimension, according to Fry [10], "is similar to the theoretical concept of namely membership". Pradhan, et al. [31] describes this dimension as the "concern or a felt relation with the other; and it is action that is also oriented towards lessening or relieving others suffering".

\section{Self-Monitoring}

The concept of self-monitoring was introduced by Mark Snyder in the 1970s. According to him, "selfmonitoring is a combination of ability and motivation". The most authoritative definition of self-monitoring was given by him. "It is the differences in the extent to which people monitor (observe, regulate, and control) the public appearances of self they display in social situations and interpersonal relationships [32]". Certain people are highly concerned about how they appear to others. These people are greatly inclines towards monitoring the people around them really closely to ensure that they behave according to them and the situation.
According to Snyder, there are two kinds of people namely, high self-monitors and low selfmonitors. High self-monitors tend to greatly regulate and modify their behaviour and interactions according to the people they interact with, whereas, low selfmonitors are incapable of regulating their behaviours and responses according to the people they interact with. Gangestad and Snyder [33] have described selfmonitoring as "a theory of expressive control specifically, as a construct that is useful for understanding and measuring the extent to which individuals strategically cultivate public appearances". According to their observation, "high self-monitors tend to be social pragmatists who are chameleon-like in adjusting the public expression of their attitudes and behaviour to fit with the expectations of others and are also likely to construct and project images with the goal of impressing others". On the other hand, "low selfmonitors are likely to attempt actively to convey to others that they present no false images".

The distinction between high self-monitors and low self-monitors was made by Snyder [34] on the basis of five factors namely, "motivation, ability, attention to cues, use of ability, and consistency of behaviour". The following is the description of each dimension as given by Snyder [2].

1. Motivation - "High self-monitors are motivated to behave in socially appropriate ways and low self-monitors are motivated to behave in self-congruent ways [34]". High self-monitors try to accommodate their behaviour according to the situation they are in and try to project themselves to be "socially appropriate", but low-self monitors always behave in a way that suits their internal self and do not compromise on it in any way and "are motivated to avoid a personally undesirable presentation of themselves[34]". They try to be the reflection of their true self, irrespective of the state of affairs.

2. Ability - This refers to the capability of an individual to adjust to situations. They have the ability to easily modify their behaviour according to the social setting they are in. "High self-monitors have a well-honed ability to know what behaviour(s) are appropriate in different social situations and change their behaviour to reflect what is appropriate across social situations[34]". They have the capacity to understand and exhibit behaviours suitable to the given setting. On the other hand, low self-monitors according to Snyder [34], "have a well-honed ability to know their own internal dispositions in different social situations and change their behaviour to reflect their internal dispositions across social situations". Irrespective of the situation, they behave in a 
way that absolutely portrays their true beliefs and values and not to please or impress others.

3. Attention to cues - According to Snyder [34], "high self-monitors focus on emotional and behavioural cues displayed by others in social situations. They are experts in "reading nuances of behaviour in others so that they can alter their own behaviour and act appropriately in social situations". High self-monitors very closely watch others and catch their emotions and mind-set through their body language, voice tone, expressions and so on. But low self-monitors, "focus on their internal dispositions and emotions in social situations as well as they introspect so that they can behave in a manner congruent with their disposition in social situations" Snyder [2]. They tend to regulate their behavior in accordance with their own beliefs.

4. Use of ability - High self-monitors use their ability to give a very meticulous representation of themselves. "This use of ability by high self- monitors is termed as strategic selfpresentation [32]". They use their ability to change their behaviour according to the demands of the situation. "Low self-monitors use their ability to alter their behaviour to display a self-presentation appropriate to their inner self in different social situations and this use of ability by low self-monitors is termed as strategic self-verification[32]". Even low selfmonitors have the capability to understand the situation, but they prefer to use this ability to act in a way that they feel is matching and suitable to their own self. This clearly states how high self-monitors and low self-monitors use their ability to read and understand the cues of people in different situations.

5. Consistency of behaviour - High selfmonitors purposefully modify their behaviour to suit the situations. They are inconsistent in their behaviour as they are concerned only about "strategic self-presentation [32]". They pay little attention to their inner self and feelings. They concentrate only on pleasing other people and do not seem to be true to themselves. Low self-monitors behave only in a way that match their beliefs and values. They don't bother too much about pleasing other people by exhibiting behaviours that suits each situation. They have consistency in their behaviour as "they are more concerned with strategic self-verification than with congruence of social situation and behaviour $[32,34]$ ”.

The concept of self-monitoring brings in the difference in the attitude of individuals and the effort that they put at work. It also brings variation in the way people view each other's work. "Self-monitoring is the blend of ability and motivation, and one of the personality variables and is about observing the social situations and controlling expressive behaviours accordingly [2, 32]". Self-monitoring is also said to have associations with several work related outcomes, including organizational commitment, retention and so on. The theory of self-monitoring is said to "give explanation about motivational, behavioural and situational components [33]”.

\section{Relational Dimension of Workplace Spirituality and Self-Monitoring}

Personality is a very important aspect in an individual's personal and professional life. It determines the behaviour of individuals which has a great impact on the genuineness of relationships created by people. According to Myers and Deiner [35], "the success and failure of interpersonal relations have a profound impact on our life satisfaction". It is also found to have direct relationship with several other positive outcomes including, well-being and overall satisfaction. Building and maintaining a connection with co-workers is a very important element that affects the satisfaction of an individual in a workplace and add on to the positivity of the workplace as well. This will increase the overall productivity of the organization as the employees will work much harder as they find the workplace really enjoyable. This sense of connection also increases the element of trust and empathy among each other and will also improve their sense of honesty and responsibility as well. All this will help reduce the conflicts which will in turn reduce the stress levels experienced by the employees. The relational dimension is focused on providing manifold positive outcomes to both the individual and the organization.

The extent to which an individual builds and maintain good relationship with his/her co-workers depends on their personality and behaviour. The creation of strong relationship with others requires the ability to control and modify behavior according to situation and people. Some individuals pay close attention to their behaviours in different social settings, whereas, some are concerned only about their inner feelings and not others'. This concept of selfmonitoring is described by Gangestad and Snyder [33] as, "a theory of expressive control, specifically, as a construct that is useful for understanding and measuring the extent to which individuals strategically cultivate public appearances". Some people are very good in building connection by exhibiting behaviours that are suited to the situation. This quality will help them to impress others quickly. These people, called high-self monitors, are experts in designing their behaviour in order to "get along with other members of the group, get ahead in terms of achieving status, and make sense of the world. 
High self-monitors are concerned about how they appear to others in different social situations. But low self-monitors attempt to display their true self irrespective of the situation. As rightly observed by Snyder and Copeland [36], "organizational settings provide the backdrop for observing a myriad of strategic self-presentation activities"'. According to Gabarro [37], "organizational work is characterized by exercises of power and authority, enacted and perceived leadership, job performance and performance assessment, attitude formation and expression, and, most important, relationships. Indeed, there is a relationship imperative at the heart of most, if not all, organizational work". These work relationships are found to be influenced by the behavioural expression of the individuals. Apart from the positive outcomes of relationships to the individuals, it is, according to McCauley and Van Velsor [38] "central to many leadership functions, such as setting direction, building commitment, and creating alignment". The concept of self-monitoring plays a tremendous role in understanding the extent to which relationships are formed and maintained by people.

Several work related outcomes have been studied by researchers with regard to self-monitoring. High self-monitors were found to be highly involved in their job as they have the capability to modify their behaviours and actions to match the scenario. But this greater involvement in their job can be said to be "an impression-management tactic" of high self-monitors [1]. A very significant finding has been put forward by Gangestad and Snyder [33]. As per their results, "high self-monitors reported lower organizational commitment as well as lower levels of interpersonal commitment and less stable social bonds". These points to the fact that high self-monitors are not genuinely attached or connected to their co-workers and their organization. They tend to change their behaviour according to the situation in order to show that they really are in sync with various scenarios.

This leads to questioning the genuineity of high self-monitors. The sense of connection in workplace spirituality is about being genuinely connected and empathetic to their co-workers. It is not seen as a tactics to impress others. Low self-monitors always project an image that reflects their true self and their beliefs and values rather than being conscious of people around them. They take little care in trying to adjust their behaviour to suit the social context. As discussed earlier, they exhibit consistency in their behaviour. There is the true element of genuineness in their character, which is the founding stone of the relational dimension of workplace spirituality. "At the most basic and individual level, workplace spirituality can be viewed as the incorporation of one's own ideals and values in the work setting. This conceptualization of workplace spirituality reflects a simple application of personal spirituality - the totality of personal values that an individual brings to the workplace and how such values influence both ethically-related and ethicallyunrelated worker interactions and outcomes [40]".

The dimension of connection, "relates to the notion of individual as a spiritual being living in a relationship with other individuals [20]". "The condition for the community includes the notion of sharing, mutual obligations, and commitments that connect one individual to another [27]. In the words of Pfefer [9], "this is an important dimension that is greatly valued by employees in the workplace that will make them themselves feel part of a larger community that is interconnected". All these points to the element of authenticity and legitimacy in being connected to the co-workers and organization, which is lacking in high self-monitors. They put a façade that they are truly build good relationship with others. But the fact is that they have falsely exhibited themselves and have not built true connection with people. Low self-monitors always portray their true self and are considered to genuinely build relationship by showing their true self. This connection is considered to be genuine as it will not change according to the situations. All this brings us to a point to question the fit of high self-monitors in the concept of workplace spirituality.

\section{Implications and Future Directions}

Though many studies have found that high self-monitors have greater chances of advancing in the organization as well as building relationships, the facts have led us to rethink on their genuineity. Especially, concepts like workplace spirituality, which is completely focused on the quality and meaning of work, connection and values, high self-monitors seem to be totally unfit. Low self-monitors stick on to their values and beliefs and most importantly they are highly true and genuine. They don't project a false image of themselves. This depiction of their true self and feelings is the vital element in developing workplace spirituality. The dimension of "connectedness to the community arise when there is a genuine feeling to help co-workers and to support and show empathy to them when facing difficult times at work [20]. This genuine connection is the major element that is found to be lacking in high self-monitors. This calls for a strong recruitment process, with a focus not just on the individual's knowledge, skill and aptitude, but also on the individual's behaviour. Inclusion of tools similar to psychometric test will help identify the behavioural characteristics. The organizations can also design tools which can capture this element.

Even though high self-monitors are found to be able, impressive and "seen as more leader-like in the eyes of others than are low self-monitors [43]", low self-monitors can be considered to build and maintain much stronger bond with their community. They use their ability to fully and truly show their inner self, values and beliefs and the element of genuineity is 
much higher in low self-monitors. So in the relational dimension of workplace spirituality, low self- monitors can be found to score much more than high selfmonitors. Future studies can focus on statistically examining this relationship and attempt to understand this contradiction. As discussed earlier, the focus of this study is limited just to the relational dimension of workplace spirituality, and in this low self-monitors can be seen to be the leaders in this and tend to enhance the relational dimension of workplace spirituality.

\section{REFERENCES}

1. Day DV, Shleicher DJ, Unckless AL, Hiller NJ. Self-monitoring personality at work: A metaanalytic investigation of construct validity. Journal of Applied Psychology. 2002 Apr;87(2):390.

2. Snyder M. Self-monitoring of expressive behavior. Journal of personality and social psychology. 1974 Oct;30(4):526.

3. Jain P. A Model for Workplace Spirituality. Advances in Economics and Business Management (AEBM).2016; 3(7); 761-764.

4. Giacalone RA, Jurkiewicz CL, editors. Handbook of workplace spirituality and organizational performance. Me Sharpe; 2003.

5. Krishnan VR. Effect of transformational leadership and leader's power on follower's duty-orientation and spirituality. Great Lakes Herald. 2007; 1(2): 48-70.

6. Kinjerski V, Skrypnek BJ. Measuring the intangible: development of the spirit at work scale. InAcademy of management proceedings. 2006;1(1) A1-A6. Briarcliff Manor, NY 10510: Academy of Management.

7. Kinjerski VM, Skrypnek BJ. Defining spirit at work: Finding common ground. Journal of organizational change management. 2004 Feb 1.

8. Giacalone RA, Jurkiewicz CL, editors. Handbook of workplace spirituality and organizational performance. Me Sharpe; 2003.

9. Pfeffer J. 'Business and the Spirit: Management Practices That Sustain Values', in R; 2003.

10. Fry LW. Toward a theory of spiritual leadership. The Leadership Quarterly.2003; 14, 693-727. http://dx.doi.org/10.1016/j.leaqua.2003.09.001

11. Mahoney MJ and GM Graci. The meanings and correlates of spirituality: Suggestions from an exploratory survey of experts. Death Studies.1999; 23: 521-8.

12. Krishnakumar S, Neck CP. The "what", "why" and "how" of spirituality in the workplace. Journal of managerial psychology. 2002 May 1.

13. Guillory WA. The living organization: "Spirituality in the workplace." Utah: Innovations; 1999.

14. Giacalone RA. 'A Transcendent Business Education for the 21st Century', Academy of Management Learning and Education.2004; 3, 415-420.

15. Blau GJ, Boal KB. Conceptualizing how job involvement and organizational commitment affect turnover and absenteeism. Academy of management review. 1987 Apr 1;12(2):288-300.

16. Bandsuch MR, Cavanagh GF. Integrating spirituality into the workplace: Theory and practice. Journal of management, spirituality \& religion. 2005 Jan 1;2(2):221-54.

17. Wong PT, Psych C. Spirituality and meaning at work. International Network on Personal Meaning, President's column. 2003 Sep.

18. Milliman J, Czaplewski AJ, Ferguson J. Workplace spirituality and employee work attitudes: An exploratory empirical assessment. Journal of organizational change management. 2003 Apr $1 ; 16(4): 426-47$

19. Brown KW, Ryan RM. The benefits of being present: mindfulness and its role in psychological well-being. Journal of personality and social psychology. 2003 Apr;84(4):822.

20. Ashmos DP, Duchon D. Spirituality at work: A conceptualization and measure. Journal of management inquiry. 2000 Jun;9(2):134-45.

21. Milliman J, Czaplewski AJ, Ferguson J. Workplace spirituality and employee work attitudes: An exploratory empirical assessment. Journal of organizational change management. 2003 Apr 1;16(4):426-47.

22. Mitroff II, Denton EA. A spiritual audit of corporate America: A hard look at spirituality, religion, and values in the workplace. San Francisco: Jossey-Bass Publishers; 1999 Oct 15.

23. Nonaka I, Von Krogh G. Perspective-Tacit knowledge and knowledge conversion: Controversy and advancement in organizational knowledge creation theory. Organization science. 2009 Jun;20(3):635-52.

24. Ipe M. Knowledge sharing in organizations: A conceptual framework. Human resource development review. 2003 Dec;2(4):337-59.

25. Rego A, Cunha MP, Souto S. Workplace spirituality, commitment, and self-reported individual performance: An empirical study. Management Research. 2007 Sep 1;5(3):163.

26. Pawar BS. Individual spirituality, workplace spirituality and work attitudes. Leadership \& Organization Development Journal. 2009 Oct 30.

27. Duchon D, Plowman DA. Nurturing the spirit at work: Impact on work unit performance. The leadership quarterly. 2005 Oct 1;16(5):807-33.

28. Wong CS, Wong YT, Hui C, Law KS. The significant role of Chinese employees' organizational commitment: Implications for managing employees in Chinese societies. Journal of World Business. 2001 Sep 1;36(3):326-40.

29. Sheng CW, Chen MC. Workplace spirituality scale design-The view of oriental culture. Business and Management Research. 2012;1(4):46-62.

30. Harrington WJ, Preziosi RC, Gooden DJ. Perceptions of workplace spirituality among professionals and executives. Employee 
responsibilities and rights journal. 2001 Sep 1;13(3):155-63.

31. Pradhan RK, Jena LK, Soto CM. Workplace spirituality in indian organisations: construction of reliable and valid measurement scale. Business: Theory and Practice. 2017 Mar 5;18:43.

32. Snyder M. Public appearances, Private realities: The psychology of self-monitoring. WH Freeman/Times Books/Henry Holt \& Co; 1987.

33. Gangestad SW and Snyder M. Self-monitoring: Appraisal and reappraisal; 2000.

34. Snyder M, Cantor N. Testing hypotheses about other people: The use of historical knowledge. Journal of Experimental Social Psychology. 1979 Jul 1;15(4):330-42.

35. Myers DG, Diener E. Who is happy?. Psychological science. 1995 Jan;6(1):10-9.

36. Snyder M, Copeland J. Self-monitoring processes in organizational settings; 1988.

37. Gabarro JJ. The development of working relationships. In J. W. Lorsch (Ed.), Handbook of organizational behavior. Englewood Cliffs, NJ: Prentice-Hall.1987; 172-189

38. McCauley CD and Van Velsor, E. (Eds.). The Center for Creative Leadership handbook of leadership development (2nd ed). San Francisco: Jossey- Bass; 2004.

39. Day DV and Schleicher DJ. Self-Monitoring at Work: A Motive-Based Perspective;2006.

40. Kolodinsky RW, Giacalone RA, Jurkiewicz CL. Workplace values and outcomes: Exploring personal, organizational, and interactive workplace spirituality. Journal of business ethics. 2008 Aug $1 ; 81(2): 465-80$

41. Kolodinsky RW, Giacalone RA, Jurkiewicz CL. Workplace values and outcomes: Exploring personal, organizational, and interactive workplace spirituality. Journal of business ethics. 2008 Aug $1 ; 81(2): 465-80$

42. Leary MR. Self-presentational processes in leadership emergence and effectiveness. In R. A. Giacalone \& P. Rosenfeld (Eds.), Impression management in the organization (pp.). Hillsdale, NJ: Erlbaum. 1989: 363-374

43. http://citeseerx.ist.psu.edu/viewdoc/download?doi= 10.1.1.831.862\&rep=rep1\&type=pdf

44. https://en.wikipedia.org/wiki/Self-monitoring (Word Count - 5001) 